\title{
A novel micromachined pump based on thick-film piezoelectric actuation
}

\author{
Michael Koch, Nick Harris, Alan G.R. Evans, Neil M. White, Arthur Brunnschweiler * \\ University of Southampton, Depariment of Electronics and Computer Science, Highfield, Southampton SOI7 1BJ, UK
}

\begin{abstract}
A new silicon-based micropump is described in this paper. The key element of the device is a thick-film/silicon micromachined hybrid actuator. The actuation principle relies on the flexure of a screen printed piezoelectric lead zirconate titanate (PZT) layer on a silicon membrane $(8 \mathrm{~mm} \times 4 \mathrm{~mm} \times 70 \mu \mathrm{m})$. An investigation into the deposition technology of the botton electrode for the piezoelectric material showed that a gold resinate or $\mathrm{Pt}$ evaporated electrode on a $500 \mathrm{~nm}$ thick $\mathrm{SiO}_{2}$ covered silicon wafer achieved best results for the membrane actuator. Inlet and outlet valves are of the cantilever type and use deep boron diffusion together with $\mathrm{KOH}$ etching. Pump rates of up to $120 \mu 1$ min ${ }^{-1}$ have been achieved. A maximum backpressure of $2 \mathrm{kPa}$ was measured when using a $600 \mathrm{~V}_{\mathrm{pp}}$ sinusoidal drive voltage at $200 \mathrm{~Hz}$ across a $100 \mu \mathrm{m}$ thick PZT layer. The pump was compared with a conventional surface mounted piezoelectric driven micropump. The conventional pump achieves a performance which was a factor of 3-6 more efficient, but does not allow mass production. (C) 1998 Elsevier Science S.A. All rights reserved.
\end{abstract}

Keywords: Micropump; PZT; Membrane actuator; Thick-film technology; Silicon micromachining

\section{Introduction}

Several types of a micropump for fluids have been published in the literature. Two major classes of these pumps are now available: membrane actuated pumps $[1-4]$ and electric field induced flow pumps $[5,6]$. Membrane actuated pumps can be further subdivided into electrostatically [3], thermopneumatically [2], bimetallically [4] and piezoelectrically [1] actuated pumps.

Micropumps with surface mounted piezoelectric membrane actuation were first reported by van Lintel et al. [1]. As small geometries require accurate positioning of the piezoelectric element on the membrane, the advantage of lowcost mass production for these devices is lost when the piezoelectric plate is glued to the surface. A big improvement is achieved if this single-step manufacturing process with complicated alignment is done in a simpler mass production method. Therefore, it was a major task in this work to find and investigate a new method for depositing the piezoelectric material onto silicon. The new technology should, however, offer both the possibility for mass production and the ability to transform a reasonable amount of electrical power into mechanical power in order to drive a micropump. This could be realised with a combination of screen-printing and silicon micromachining. Other methods of depositing PZT with sol-

* Corresponding author. Tel.: +44-1703-593737; fax: + 44-1703-593029 gel deposition [7] or physical vapour deposition [8] have been described, but lack the possibility of producing thick layers of $100 \mu \mathrm{m}$ and more. The basic principles and some simulations of the thick-film-on-silicon hybrid actuator have already been reported [9] but this is the first presentation of a working micropump using hybrid actuation.

\section{Fabrication}

A diagram of the micropump is shown in Fig. 1. The pump consists of a stack of three silicon chips. The two lower layers form the inlet and outlet valves. The top layer is the membrane actuator. The operation of the pump depends on the oscillating membrane varying the volume inside the chamber. When the chamber volume is increased at low actuation frequencies,

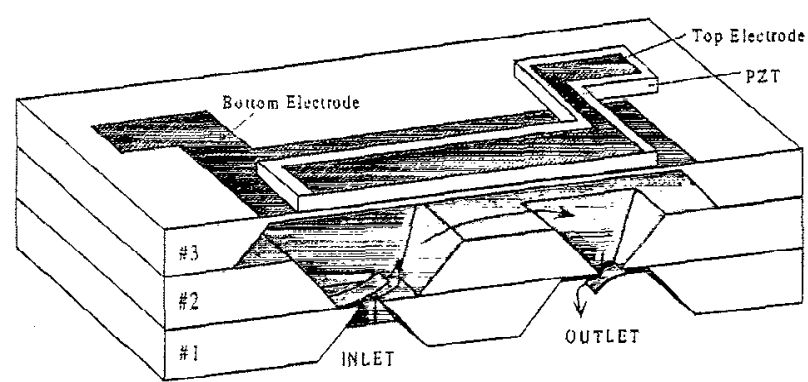

Fig. 1. Hybrid actuated micropump stack. 
liquid is sucked through the inlet valve while the outlet remains shut. If the chamber volume decreases, the inlet valve closes and liquid is pumped through the outlet.

\subsection{Passive cantilever valves}

The fabrication of the passive cantilever valves has already been presented elsewhere [10]. It is based on a $\mathrm{B}^{+}$anisotropic etch stop layer for the definition of the cantilever and the creation of a conical duct on the same wafer. For ease of testing, two identical chips were placed on top of each other to complete both inlet and outlet valve.

\subsection{Membrane actuator}

Standard silicon micromachining processes were used for the membrane. A $70 \mu \mathrm{m}$ thick membrane was formed with a time-controlled etch in $\mathrm{KOH}$ at $70^{\circ} \mathrm{C}$ and $30 \mathrm{wt} . \%$ using LPCVD silicon nitride as an etch mask. After removal of the etch mask the wafers were covered with a $500 \mathrm{~nm}$ thick oxide. This produces an insulating layer between substrate and actuator. Processing was then continued with thick-film technology where mass production of up to $4 \mathrm{in}$. wafers is possible. In our case, the printing was done on quartered 4 in. silicon wafers to allow for several tests per wafer. Good alignment between thick-film and silicon micromachined structures is achieved with alignment marks in each corner of the quartered wafer and the screens.

The generation of a PZT capacitor between two electrodes is described as follows: First, a cermet gold bottom electrode of $10 \mu \mathrm{m}$ thickness was printed, dried at $130^{\circ} \mathrm{C}$ for $10 \mathrm{~min}$ and fired in a conveyor belt furnace at a peak temperature of $950^{\circ} \mathrm{C}$ for $1 \mathrm{~h}$. Fig. 1 shows that the bottom electrode has been made larger than the diaphragm. The reason for this was to reduce stress in the diaphragm due to a mismatch in the temperature coefficients (thermal coefficient of expansion: $\operatorname{TCE}(\mathrm{Si})=2.33 \times 10^{-6} \mathrm{~K}^{-1}$, TCE $\left(\mathrm{Al}_{2} \mathrm{O}_{3}\right)=6.8 \times 10^{-6}$ $\mathrm{K}^{-1}$. TCEs of normal inks are usually designed to match alumina, TCE (bulk PZT) $=2.5 \times 10^{-6} \mathrm{~K}^{-1}$ ). Designs with $4 \mathrm{~mm} \times 8 \mathrm{~mm}$ bottom electrodes on $4 \mathrm{~mm} \times 8 \mathrm{~mm} \times 70 \mu \mathrm{m}$ sized membranes led to maxmum deflections in the centre of the membrane of approximately $30 \mu \mathrm{m}$. For $5 \mathrm{~mm} \times 9 \mathrm{~mm}$ bottom electrodes, part of the stress is absorbed by the bulk$\mathrm{Si}$. The bending was around $7 \mu \mathrm{m}$ and thus significantly reduced. Both measurements were taken after the wholc printing cycle of bottom electrode $(10 \mu \mathrm{m}), \mathrm{PZT}(\sim 100 \mu \mathrm{m})$ and top electrode $(10 \mu \mathrm{m})$.

After this, the wafer was put through two cycles of double printing, drying $\left(10 \mathrm{~min}\right.$ at $\left.130^{\circ} \mathrm{C}\right)$ and firing of a special PZT ink ( $1 \mathrm{~h}$ including heating and cooling time at $950^{\circ} \mathrm{C}$ ). This ink contains $95 \% \mathrm{PZT} 5 \mathrm{SH}$ powder and $5 \%$ leadborosilicate powder as a binder. Añ organic vehicle (ESL 400) has to be added to control the paste viscosity and hence produce a screen-printabie ink. With a total of four printing steps a thickness of approximately $100 \mu \mathrm{m}$ was achieved. Finally, a gold top electrode is printed with the same process as before.
Due to condensation and subsequent diffusion of lead on the silicon surface during firing, the intermediate oxide between $\mathrm{Si}$ and PZT becomes conductive [11]. It is therefore necessary to deposit the top electrode entirely on the fired PZT layer. The layout for the top electrode as depicted in Fig. 1 guarantees that top and bottom electrodes are isolated.

Visual inspection and scratch-tests were done to judge adhesion of the printed layers after firing. As peeling off did not occur during scratch tests, adhesion of the bottom electrode to Si-substrate and PZT to Au-electrode seems to be good. Finally, the PZT is polarized with an electric field of 3 $\mathrm{MV} \mathrm{m}{ }^{-1}$ at $130^{\circ} \mathrm{C}$ for $24 \mathrm{~h}$. In order to verify a successful polarization, charge measurements were made to determine the $d_{33}$ coefficient of the screen printed PZT. Screen printed samples without membranes were mechanically stressed with a constant force and the generated charge was amplified and measured. From this, the $d_{33}$ value could be determined. Furthermore, displacement measurements at the centre of the membrane were taken with an optical fibre laser interferometer. The resolution of this type of interferometer is nominally a quarter of a wavelength or $158 \mathrm{~nm}$ for a helium neon laser with a wavelength of $633 \mathrm{~nm}$. For reference purposes, the deflection of a surface mounted bulk PZT actuator $(6.25 \times$ $3.25 \times 0.2 \mathrm{~mm}$ ) was determined to be approximately 1100 $\mathrm{nm}$ at $100 \mathrm{~Hz}$ and $1700 \mathrm{~nm}$ at $3 \mathrm{kHz}$.

\subsection{Tests with different bottom electrodes}

Experiments have been carried out with different insulation layers and inks for the bottom electrode [9]. Three different surface layers were tested:

- Native oxidized surface

- $500 \mathrm{~nm}$ thick layer of thermally grown $\mathrm{SiO}_{2}$

- $160 \mathrm{~nm}$ thick layer of $\mathrm{Si}_{3} \mathrm{~N}_{4}$ on $80 \mathrm{~nm}$ of $\mathrm{SiO}_{2}$

In parallel several different types of thick-film ink for electrodes were investigated:

- Resinate gold, platinum

- Cermet silver-palladium, gold, platinum

- Evaporated gold, platinum

Initial experiments confirmed a link between high dielectric values of the fired PZT layer and good mechanical actuation performance. Therefore, the dielectric constant was taken as a figure of merit for the quality of the actuator.

The attraction of using a resinate ink is its possibility to create reiatively thin layers in the range of $0.5 \mu \mathrm{m}$. However, all bottom electrodes of both resinate gold and resinate platinum printed onto the silicon wafer with an intermediate 500 $\mathrm{nm}$ thick silicon dioxide layer showed local failures in conductivity aftcr firing. Therefore, no further attempts with resinate inks have been done. As well, printing the PZT onto the silicon nitride substrate was unsuccessful for all electrode materials due to a reaction that produced bubbles being trapped under the ink.

As silver palladium inks are cheaper than other inks, AgPd was investigated first. Silver palladium was successfully printed on $500 \mathrm{~nm}$ wet $\mathrm{SiO}_{2}$ and native oxide covered silicon 
wafers, although there was a certain change in colour of the P7T. The dielectric constant was between 50 and 70 , independent of the substrate insulator (native oxide and wet $\mathrm{SiO}_{2}$ ). This has to be compared with the bulk value for PZT$5 \mathrm{H}$ which is 3400 at room temperature [12], being nearly 60 times larger. No displacement of the membranes could be measured, as a signal was not distinguishable from noise. The membrane actuator was, however, audible in the frequency range between 8 and $12 \mathrm{kHz}$. The same inks have been printed on alumina substrates, where the dielectric constant increased to values of $373 \pm 11$. It is well known in thick-film processing that silver migrates [13]. Thus, it seems possible that the silver migration causes the coloration and the subsequent reduction in the dielectric constant. As the dielectric constant was rather low compared to the other experiments, no further investigations have been done to clarify the cause of this behaviour.

Evaporating gold onto silicon is a fully compatible thinfilm process. The deposition of $0.5 \mu \mathrm{m}$ gold was done with a standard evaporator on $500 \mathrm{~nm}$ silicon dioxide covered silicon wafers with an intermediate $40 \mathrm{~nm}$ thick $\mathrm{Cr}$ layer to improve adhesion of the gold layer to the substrate. After firing the PZT, the gold changed its colour from metallic to dull. The top electrode for the PZT capacitor was printed with a cermet gold ink, as thin-film deposition and patterning is impossible on top of the rough and rather high PZT layer. The dielectric constant of the PZT layer on thin-film gold reached a value of $126 \pm 7$ which was already an improvement compared to the AgPd screen printed electrodes. Yet, this is still a factor of 24 less than the bulk value.

The next tests have been done with cermet gold ink (ESL $8836 \mathrm{C} 35$ ). The dielectric constant of PZT with a cermet gold bottom electrode on $500 \mathrm{~nm}$ silicon dioxide increased to $461 \pm 26$. This figure of merit is only a factor of 7 off the bulk values. The displacement measurements of a $8 \times 4 \times 0.07 \mathrm{~mm}$ silicon membrane with a $7 \times 3 \times 0.09 \mathrm{~mm}$ PZT layer gave $450 \mathrm{~nm}_{\mathrm{pp}}$ at $100 \mathrm{~V}_{\mathrm{pp}}$ for low frequencies around $500 \mathrm{~Hz}$ and $650 \mathrm{~nm}$ at frequencies around $3 \mathrm{kHz}$. This is around half the value of a surface mounted device. Apart from the deflection, the $d_{33}$ values of the devices were measured. The piezoelectric charge constant for PZT on cermet gold electrodes was 103 $\mathrm{pC} \mathrm{N}^{-1}$ or $1 / 6$ of the bulk value [12].
Also, a cermet platinum layer (ESL 5545) was investigated as bottom electrode. The process steps were done in the same way as above. The top electrode was realised with a low temperature firing ink (ESL 590-G) to reduce the thermal load. This electrode was printed twice, dried at $135^{\circ} \mathrm{C}$ for $10 \mathrm{~min}$ and fired at $570^{\circ} \mathrm{C}$ in a conveyor belt furnace for $1 \mathrm{~h}$. After the whole printing experiment, the dielectric constant of the PZT was unexpectedly low at $58 \pm 8$. Like with the $\mathrm{AgPd}$ electrodes, the actuator was audible in the frequency range between 8 and $12 \mathrm{kHz}$ but no displacement could be measured. As both figures of merit are rather low, further experiments have not been carried out for Pt cermet inks.

The last layer investigated was an evaporated Pt thin film. It was deposited on top of a $500 \mathrm{~nm}$ thick wet $\mathrm{SiO}_{2}$ layer with an intermediate $40 \mathrm{~nm}$ thick Ti layer to improve adhesion. The film thickness was $500 \mathrm{~nm}$ and screen printing of the PZT was done directly on top. The top electrode was a UV curable polymer ink (ESL 1109-S), to reduce the thermal load even further. It was dried at $90^{\circ} \mathrm{C}$ for $30 \mathrm{~min}$, exposed with UV light for $10 \mathrm{~min}$ and then cured at $150^{\circ} \mathrm{C}$ for $2 \mathrm{~h}$. With this technique, the largest dielectric constants have been achieved. The figure of merit was $485 \pm 67$, which was slightly larger than the values obtained with the gold cermet ink. For $85 \mu \mathrm{m}$ thick PZT at low actuation frequencies the peak-to-peak displacement was determined to be around 350 $\mathrm{nm}$ for $100 \mathrm{~Hz}$, rising to $600 \mathrm{~nm}$ at $3 \mathrm{kHz}$. This is in the range which was obtained with gold cermet electrodes. A $135 \mu \mathrm{m}$ thick PZT layer on Pt could only achieve $350 \mathrm{~nm}$ peak-topeak displacement at $3 \mathrm{kHz}$, being half the value of the thinner layer.

In summary, the best results were obtained with the cermet gold electrode on $500 \mathrm{~nm} \mathrm{SiO} 2$. All further experiments refer to this type of electrode. A summary of the results can be found in Table 1.

\section{Measurement results}

The micropump was tested in a jig with ethanol as the test liquid (Fig. 2). For ease of mounting the two lower layers containing the cantilever valves were placed on top of each other after cleaning with isopropylalcohol. A $1 \mathrm{~mm}$ thick silicone layer between the valves and the actuator was nce-

Table 1

Summary of the screen-print experiments of a hybrid actuator on $\mathrm{SiO}_{2}$

\begin{tabular}{|c|c|c|c|c|c|c|}
\hline Bottom electrode & AgPd cermet & Au evap. & Au cermet & Pt cermet & Pt evap. & $\mathrm{Ag}$ \\
\hline PZT binder & $5 \% \mathrm{BS}$ & $5 \% \mathrm{BS}$ & $5 \% \mathrm{BS}$ & $5 \% \mathrm{BS}$ & $5 \% \mathrm{BS}$ & bulk mat. [12] \\
\hline Top electrode & AgPd cermet & Au cermet & Au cermet & Low T cermet & LowT UV curable & $\mathrm{Ag}$ \\
\hline Dielectric constant & $60 \pm 10$ & $126 \pm 7$ & $461 \pm 26$ & 58 & $485 \pm 67$ & 3400 \\
\hline Displacement in $\mathrm{nm}_{\mathrm{pp}}$ & $x_{1}$ & $x_{\mathrm{z}}$ & $450-650$ & $x_{1}$ & $350-600$ & - \\
\hline$d_{33}\left(p C N^{-1}\right)$ & $x_{2}$ & $x_{2}$ & 103 & $x_{2}$ & 95 & 641 \\
\hline
\end{tabular}

$x_{1}$ : Not measurable but audible between 8 and $12 \mathrm{kHz}$.

$x_{2}$ : Not measured.

BS: Lead zinc borosilicate glass. 
Table 2

Comparison between surface mounted and hybrid actuator (gold cermet bottom electrode)

\begin{tabular}{llll}
\hline Type & Displacement $\left(\mathrm{nm}_{\mathrm{pp}}\right)$ & Maximum pumprate $\left(\mu \mathrm{min}^{-1}\right)$ & Maximum backpressure $(\mathrm{kPa})$ \\
\hline Hybrid actuator $7 \times 3 \times 0.1 \mathrm{~mm}$ & $450-650$ at $100 \mathrm{~V}_{\mathrm{pp}}$ & 120 at $600 \mathrm{~V}_{\mathrm{pp}} 200 \mathrm{~Hz}$ & 2 at $600 \mathrm{~V}_{\mathrm{pp}} 200 \mathrm{~Hz}$ \\
Surface mounted $6.25 \times 3.25 \times 0.2 \mathrm{~mm}$ & $1100-1700$ at $100 \mathrm{~V}_{\mathrm{pp}}$ & 150 at $200 \mathrm{~V}_{\mathrm{pp}} 200 \mathrm{~Hz}$ & 4 at $200 \mathrm{~V}_{\mathrm{pp}} 200 \mathrm{~Hz}$ \\
\hline
\end{tabular}

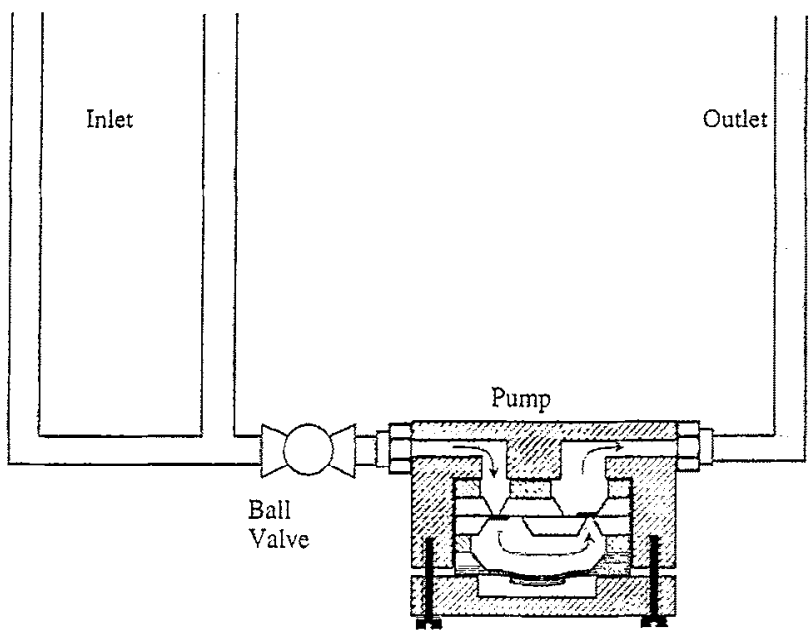

Fig. 2. Test setup of the micropump.

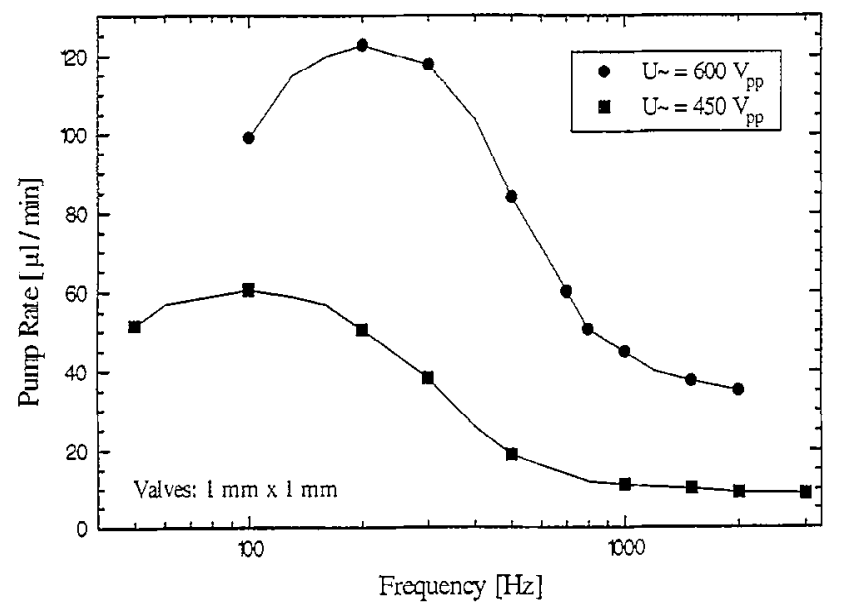

Fig. 3. Frequency dependence of the micropump with thick-film-on-silicon actrator at zero backpressure.

essary to seal the pump chamber. The cantilevers were $1 \times 1$ $\mathrm{mm}$ in size sitting on a cone with a minimum opening of $130 \times 130 \mu \mathrm{m}$.

The frequency dependence of the pump rate at zero backpressure is shown in Fig. 3 for two different actuation voltages $\left(450 \mathrm{~V}_{\mathrm{pp}}\right.$ and $\left.600 \mathrm{~V}_{\mathrm{pp}}\right)$. A maximum pump rate of $61 \mu \mathrm{l}$ $\min ^{-1}$ and $122 \mu \mathrm{lmin}^{-1}$, respectively, was achieved at frequencies of $100 \mathrm{~Hz}$ and $200 \mathrm{~Hz}$. The backpressure dependence is depicted in Fig. 4 for $600 \mathrm{~V}_{\mathrm{pp}}$ and $200 \mathrm{~Hz}$. An almost linear drop can be observed and a maximum backpressure of $2 \mathrm{kPa}$ is achievable.

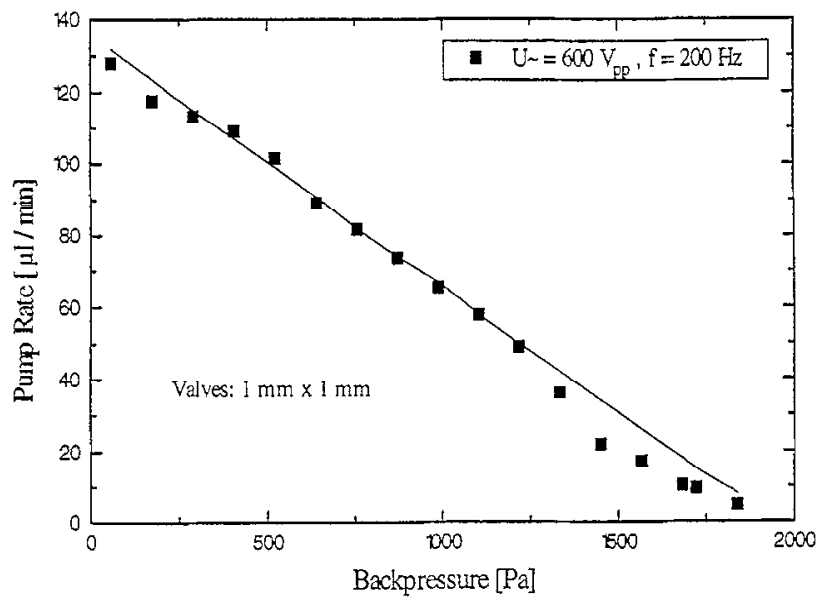

Fig. 4. Backpressure dependence of the micropump with thick-film-onsilicon actuator at $200 \mathrm{~Hz}$ and $600 \mathrm{~V}_{\mathrm{pp}}$ actuation.

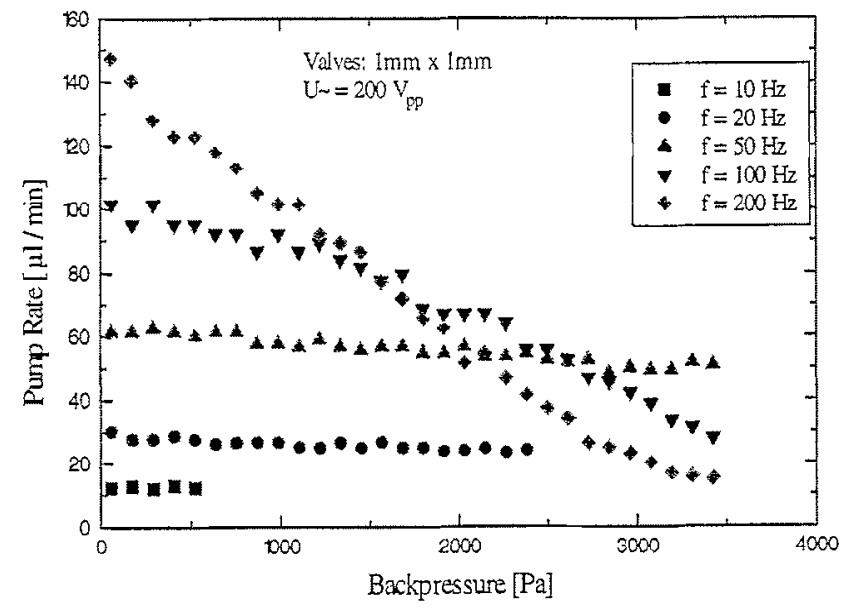

Fig. 5. Backpressure dependence of the micropump with surface mounted actuator.

Tests with an identical setup were done with the surface mounted PZT layer for comparison. Here, a maximum pump rate of $150 \mu 1 \mathrm{~min}^{-1}$ was measured for $200 \mathrm{~V}_{\mathrm{pp}}$ and $200 \mathrm{~Hz}$ (see Fig. 6). The maximum backpressure at this setup was determined to $4 \mathrm{kPa}$ (Fig. 5). It is interesting to see the change in behaviour of the pump rate with respect to backpressure. Whereas low actuation frequencies allow extrapolated pump rates of up to $20 \mathrm{kPa}$, the behaviour shifts to smaller maximum backpressures at higher frequencies. At the same time, increasing pump rates for zero backpressure were achieved 


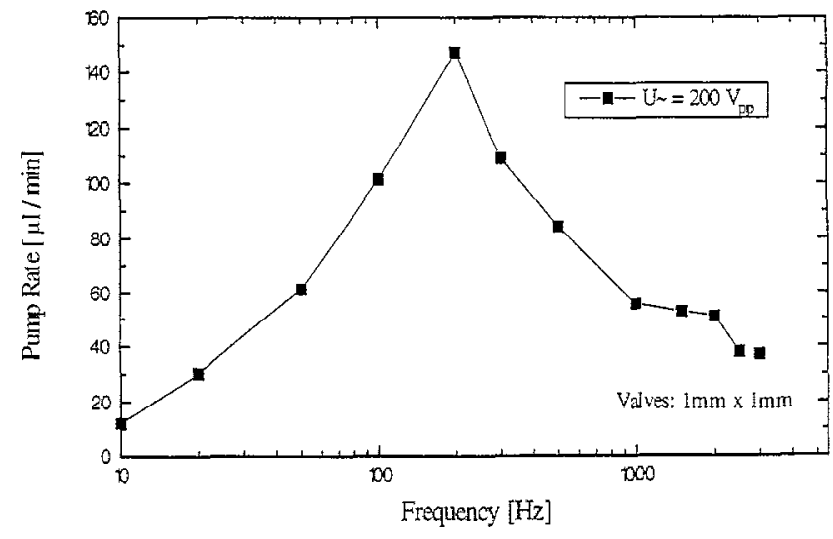

Fig. 6. Frequency dependence of the micropump with surface actuator at zero backpressure.

by increasing the pump frequency to $200 \mathrm{~Hz}$. All results are summarized in Table 2.

\section{Conclusions}

The first generation of thick-film-on-silicon PZT actuators and pumps achieves approximately $1 / 6-1 / 3$ of the performance of surface mounted devices. The mechanical power of the first hybrid actuators is already large enough to drive a micropump and the technology itself has the advantage of introducing mass production for various powerful actuators. The working micropump driven with the thick-film/silicon micromachining PZT actuator could be exploited in medicine as a cheap disposable pump for drug dispensing. However, further work is needed to show compatibility between medical drugs like insulin and the pump.

\section{Acknowledgements}

The authors would like to thank the staff of the University of Southampton Microelectronics Centre and the Thick Film Unit for help with micromachining and PZT printing.

\section{References}

[1] H.T.G. van Lintel, F.C.M. vande Pol, S. Bouwstra, Piezoelectric micropump based on micromachining of silicon, Sensors and Actuators $15(2)(1988)$ 153-167.

[2] F.C.M. vande Pol, H.T.G. van Lintel, M. Elwenspoek, J.H.J. Fluitman, Thermopneumatic micropump based on micro-engineering techniques, Sensors and Actuators A $21(1-3)(1990)$ 198-202.

[3] R. Zengerle, M. Richter, Simulation of microfluid systems, J. Micromechanics Microeng. A 4 (4) (1994) 192-204.

[4] G. Zhan, T.Lo, L. Liu, P. Tsien, A silicon membrane micropump with integrated bimetallic actuator, Chin. J. Electron. 5 (2) (1996) 29-35.

[5] A. Richter, A. Plettner, K.A. Hoffman, H. Sandmaier, Electrohydrodynamic pumping and flow measurement, Proc. IEEE Micro Electro Mechanical Systems, Nara, Japan, 1991, pp. 271-276.

[6] A. Manz, D.J. Harrison, J.C. Verpoote, H. Ludi, H.M. Widmer, Inte- grated electroosmotic pumps and flow manifolds for total chemical analysis systems, Proc. Transducers, San Francisco, USA, 1991, pp. 939-941.

[7] Y.L. Tu, S.J. Milne, A study of the effects of process variables on the properties of PZT films produced by a single-layer sol -gel technique, J. Mater. Sci. 30 (10) (1995) 2507-2516.

[8] P.H. Ansari, A. Safari, In-situ deposition of PZT thin-films by RF magnetron sputtering, Integrated Ferroelectrics $7(1-4)$ (1995) 185193.

[9] M. Koch, N. Harris, A.G.R. Evans, N.M. White, A. Brunnschweiler, A novel micropump design with thick-film piezoelectric actuation, Measurement Sci. Technol. 8 (1) (1997) 49-57.

[10] M. Koch, A.G.R. Evans, A. Brunnschweiler, Simulation and fabrication of micromachined cantilever valves, Proc. 10th European Conference on Solid-State Sensors, Leuven, Belgium, 1996, pp. 849-852.

[11] R. Maas, M. Koch, N. Harris, N.M. White, A.G.R. Evans, Thick-film printing of PZT onto silicon, Mater. Lett. 31 (1997) 109-112.

[12] H. Schaumburg, Sensoren, B.G. Teubner, Stuttgart, 1992.

[13] S.J. Stein, C. Huang, P. Bless, Low-cost, high reliability multilayers made with silver containing thick films, Electro-Science Laboratories, Inc., internal publication, 1996.

\section{Biographies}

Michael Koch was born in Ingolstadt, Germany in 1970. He received the Dipl.-Ing. (FH) degree from the Fachhochschule Regensburg, Germany in 1994 and is currently studying towards the Ph.D. degree in the Department of Electronics and Computer Science at Southampton University, England. At present he is a research assistant for micromachining in the same department. His main interest is in micromachining and computer modelling in general and in the microfluidic area in particular. This includes microvalves, micropumps and other microfluidic devices like mixers, etc.

Nick Harris graduated from Bath in 1988 with an honours degree in electrical and electronic engineering, closely followed by a MEng in 1989 in association with Marconi Communications. He then spent two years overseas with a seismic company as a field engineer, before working in a teaching capacity in the Department of Mechanical Engineering at Southampton. This was followed by three years as a research assistant in that department investigating ultrasonic communication through water filled pipes, for part of which a Ph.D. was awarded in 1997 . He is now a research fellow in the Intelligent Sensor Microsystems Group of the Electronics and Computer Science Department, researching thick film ferroelectric materials for use in sensors and actuators. He is a chartered engineer, and a member of the IEE.

Alan Evans received the B.Sc. degree in physics from Liverpool University, UK, in 1966 and the D.Phil. degree from Oxford University in 1969. He is at present a Reader in the Department of Electronics and Computer Science at Southampton University, England. His research interests include micromachined silicon sensors and actuators, novel fabrication technology for CMOS devices and conduction mechanisms in polysilicon. In recent years he has been responsible for the supervision of industrially funded projects for the 
development of micromachined pressure sensors using both bulk and polysilicon diaphragms, and more recently has supervised the development of micromachined probes for atomic force microscopy.

Neil White obtained his doctorate from the University of Southampton in 1988 for a thesis entitled 'A study of the piezoresistive effect in thick-film resistors and its application to load transduction'. A paper based on this work was awarded the 1989 Educational Prize from the International Society for Hybrid Microelectronics (ISHM). White was employed as a research fellow until 1990 when he was appointed as lecturer within the Intelligent Sensor Microsystems Research Group. His professional qualifications include Chartered Engineer and Chartered Physicist and he is involved with various committees in the IEE and IOP. Currently he is Chairman of the ISAT Group of the Institute of Physics and is also a member of Professional Group J1 of the
IEE. He is also Research Director of the University of Southampton Institute of Transducer Technology (USITT).

Arthur Brunnschweiler was born in Manchester, England, in 1936. He received the B.A. degree from Cambridge University in 1956, the M.S. degree from Pennsylvania State Univcrsity in 1960, and the Ph.D. degree from the University of Manchester Institute of Science and Technology in 1966. From 1960 to 1964 he was cmploycd in the Camera Tube Research Department of the English Electric Valve Company, Chelmsford, England, and since 1966 he has been on the academic staff of Southampton University, England, where he is currently Senior Lecturer in the Department of Electronics and Computer Science. His research and teaching interests include most areas of microelectronics, particularly device and circuit design. He has acted as consultant to several industrial companies and his present duties include the management of the Microelectronics Industrial Unit at Southampton University. 